\title{
DOS EJEMPLOS DE INTERVENCIÓN EN EL ACONDICIONAMIENTO DE TEATROS EN MADRID: EL TEATRO DE ÓPERA Y LA SALA DE CONCIERTOS. ESPAÑA
}

(TWO EXAMPLES OF INTERVENTION AT CONDITIONNING OF THEATRE IN MADRID: OPERA THEATRE AND THE CONCERT HALL. SPAIN)

Felipe Delgado Laguna, Arquitecto

E. A.: Alejandro Casona, 3

El Teatro de Ópera "La Zarzuela"

La Sala de Conciertos El Teatro "Monumental"
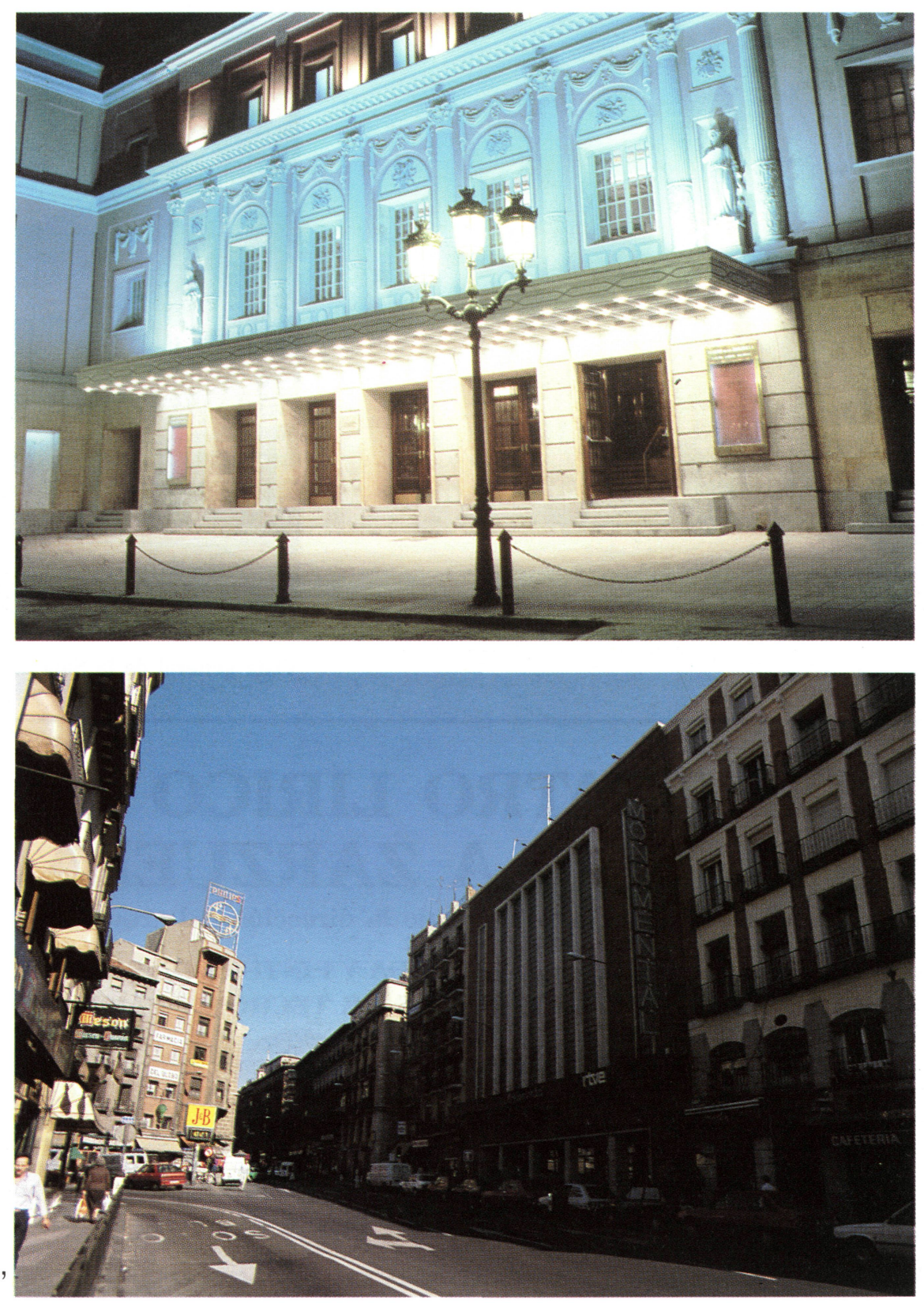


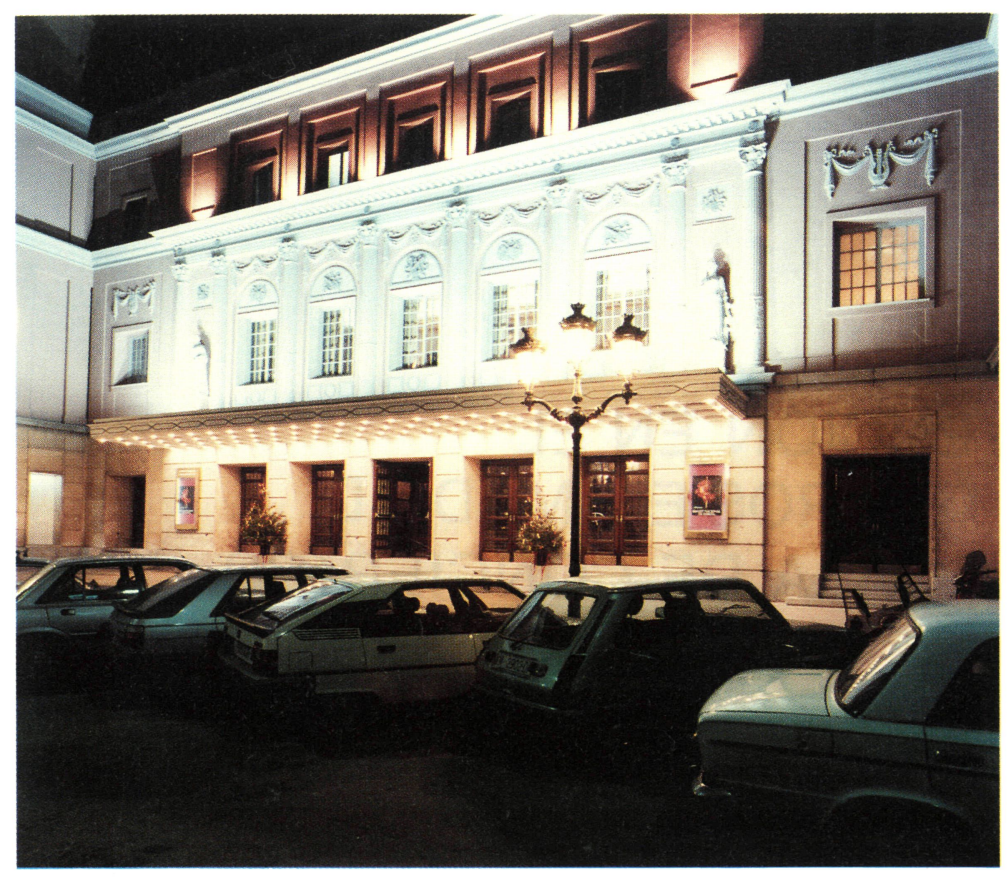

Fachada Principal.

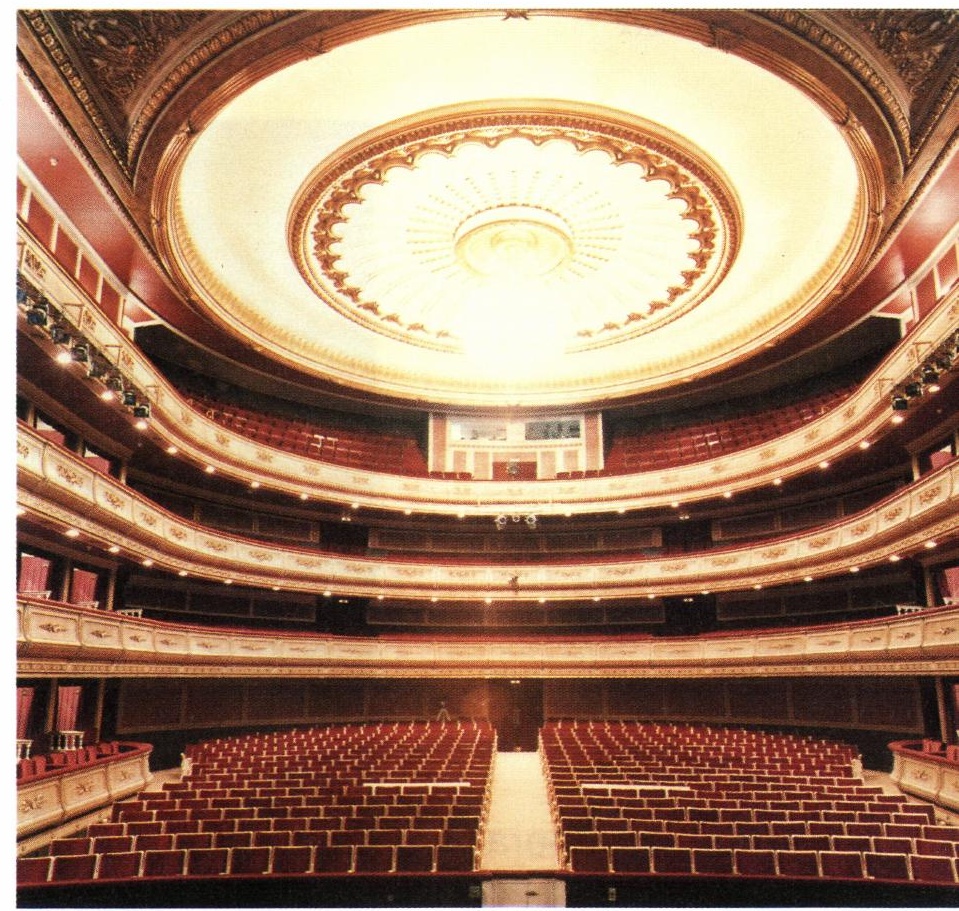

Vista general de la Sala desde el escenario.

\section{EL TEATRO LÍRICO NACIONAL LA ZARZUELA}

Ha sido restaurado en su totalidad bajo la dirección del arquitecto don Felipe Delgado Laguna Las obras de limpieza y restauración de FACHADA Y PINTURA DE SALA, PALCOS, VESTIBULOS Y PASILLOS, así como LOS DORADOS Y DECORADOS DE TECHOS Y PARAMENTOS, han sido realizados por:

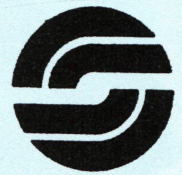

GENERAL ARANDA, 9 